\title{
Cultura organizacional: sinergias e alergias entre Hofstede e Trompenaars*
}

\author{
Daniel Pacheco Lacerda**
}

Sumário: 1. Introdução; 2. Referencial teórico; 3. As dimensões culturais de Geert Hofstede; 4. As dimensões culturais de Fons Trompenaars; 5. Sinergias e alergias entre as dimensões propostas por Hofstede e Trompenaars.

Summary: 1 . Introduction; 2. Literature review; 3 . Hofstede's cultural dimensions; 4. Trompenaars' cultural dimensions; 5. Synergies and allergies between Hofstede's and Trompenaars' proposed dimensions

Palavras-chave: dimensões culturais; estudo de caso; cultura organizacional.

KEY WORDs: cultural dimensions; study case; cultural organization.

Entre os diferentes elementos a serem considerados na gestão atualmente, os aspectos culturais têm se colocado na centralidade das discussões organizacionais. Essa posição deriva do fato de que a vantagem competitiva sustentável se origina da compreensão, respeito e utilização das diferenças de hábitos, práticas, pontos de vistas e competências. Empresas com atuação local ou global precisam atentar para as características oriundas de seu capital humano. O presente trabalho busca apresentar algumas evidências das implicações culturais a partir do prisma das dimensões culturais. Para isso é realizada uma breve revisão sobre o tema, em seguida são discutidas algumas repercussões para as organizações.

Organizational culture: synergies and allergies between Hofstede and Trompenaars

Among the different elements to be considered in management, cultural aspects have been placed in the central of the organizational discussions. This position

\footnotetext{
* Artigo recebido em jun. 2010 e aceito em out. 2010.

** Pesquisador do Programa de Pós-graduação em Engenharia de Produção e Sistemas-PPGEPS, Universidade do Vale do Rio dos Sinos (Unisinos). Coordenador acadêmico do Grupo de Pesquisa em Modelagem para Aprendizagem (GMAP/Unisinos). Coordenador do bacharelado em engenharia de produção (EP/Unisinos). Endereço: Universidade do Vale do Rio dos Sinos (Unisinos). Programa de Pós-graduação em Engenharia de Produção e Sistemas (PPGEPS/Unisinos). Av. Unisinos, 950 - Cristo Rei — CEP 93022-000, São Leopoldo, RS, Brasil. E-mail: dlacerda@ unisinos.br.
} 
derives of the fact that the sustainable competitive advantage originates from the understanding, respect and use of the different habits, practices, points of view and competences. Companies acting local or global need to look at the characteristics originated from your human capital. In this sense that the present work presents some evidences of the cultural implications, looked from the prism of cultural dimensions. A short revision of the theme was briefly analyzed and discussed under the light of the presented theoretical references.

\section{Introdução}

"Cultura não existe. De alguma forma valores não existem, dimensões não existem" (Hofstede, 2002:1359). À primeira vista essa frase pode causar algum impacto. Entretanto, Hofstede (2002) argumenta que a cultura e suas dimensões são construtos utilizados para explicar e prever comportamentos. Nesse sentido o autor define cultura como "Uma programação mental coletiva que distingue um grupo ou uma categoria de pessoas, de outro" (Hofstede e Mccrae, 2004:58). Conforme Trompenaars (1994), cultura é um sistema comum de significados, que mostra o que se deve prestar atenção, como se deve agir e o que se deve valorizar.

Essas definições de cultura apresentam alguns elementos comuns. Um primeiro elemento que pode ser destacado é que uma determinada cultura apenas faz sentido em um coletivo e não individualmente. Apesar disso, os efeitos de uma cultura sobre o indivíduo fazem sentido. Um segundo elemento é de que há diferenças entre grupos em termos de "programação mental", nas palavras de Hofstede, ou, nas palavras de Trompenaars (1994:21), "um sistema comum de significados". Em termos de definição, Trompenaars parece avançar para as implicações da cultura nos indivíduos. O autor evidencia isso quando afirma que se deve "prestar atenção em como devemos agir ou o que devemos valorizar".

Atualmente, com a evolução da globalização através do fluxo intenso de pessoas e informações, as fronteiras regionais, físicas e culturais se diluem (Canen e Canen, 2005). Assim, as diferenças culturais existentes e que eram percebidas em situações comerciais ou de viagens, por exemplo, passam a ter maiores implicações. Essas implicações se amplificam de acordo com o crescimento das empresas multinacionais (brasileiras, ou não) e se expressam nas atividades de negócios que envolvem as diferentes culturas (em sentido amplo, entre países, empresas, regiões, por exemplo). Embora as diferenças existam, as formas como as organizações as tratam podem, por um lado, ser 
um fator de geração de uma vantagem competitiva ou, por outro lado, inviabilizar operações internacionais, operações industriais ou outras atividades organizacionais.

As características culturais podem ser evidenciadas através de dimensões culturais. Essas dimensões procuram explicar alguns padrões de comportamento existentes na cultura de um país e/ou organização. A distinção entre organização e país aparentemente é necessária dado que, no contexto atual, as organizações têm caráter transnacional com diferentes tipos de acionistas e colaboradores. Assim, embora fisicamente localizada em uma região, a organização pode apresentar características distintas desse local.

Nesse sentido, Hofstede e Trompenaars apresentam algumas dimensões culturais. A aplicação dessas dimensões em diferentes contextos tem sido objeto de trabalho de diversos autores (Blanton e Barbuto Jr., 2005; Mello e Stank, 2005; O'Keefe e O'Keefe, 2004; Chang, 2003; Lagrosen, 2003; Harvey, 1997). As contribuições das dimensões propostas servem a análises que vão do nível do local de trabalho (Blanton e Barbuto Jr., 2005) à escala de comparação entre países (O'Keefe e O’Keefe, 2004).

Neste contexto o objetivo central deste trabalho é evidenciar as implicações organizacionais a partir do prisma das dimensões culturais. Para isso é realizada uma breve revisão sobre o tema chamando a atenção, primeiramente, para as dimensões culturais e um breve cotejo entre estas. Por fim, são realizadas algumas discussões e implicações das dimensões culturais para as organizações.

\section{Referencial teórico}

O referencial teórico desse trabalho não busca ser exaustivo. Tem-se por objetivo apresentar sucintamente os elementos necessários para sua compreensão. Assim, inicia-se apresentando brevemente as dimensões culturais segundo Hofstede e Trompenaars. Na sequência, cotejam-se as dimensões do ponto de vista de Hofstede e da proposta de Trompenaars.

\section{As dimensões culturais de Geert Hofstede}

As dimensões culturais definidas por Hofstede se originaram em uma survey realizada na IBM e suas subsidiárias de diferentes países (Hofstede e McCrae, 
2004). A pesquisa abrangeu 71 países, tendo sido realizada entre 1967 e 1973, e ao todo 117 mil observações (questionários) foram obtidas. Diferentes etapas de validação da pesquisa foram realizadas; as etapas, os procedimentos e a identificação estão descritos em dois livros Culture's consequences: international differences in work-related values e Cultures consequences: comparing values, behaviors, institutions and organizations across nations.

Conforme Hofstede (1983), sua pesquisa sobre as dimensões da cultura tinha dois objetivos: i) desenvolver uma terminologia comumente aceitável, bem definida e empiricamente fundamentada para descrever culturas; e ii) analisar os dados coletados de forma sistemática e sobre um significativo número de culturas, ao invés de utilizar apenas impressões. As dimensões culturais emergiram através de estatísticas multivariadas (análise fatorial) e de embasamento teórico (Hofstede, 1983, 1978). A análise evidenciou que 50\% da variância das respostas entre os países poderiam ser explicadas por três fatores (individualismo e coletivismo, distância do poder, resistência à incerteza). A quarta dimensão emergiu das pesquisas de antropólogos e sociólogos e diz respeito à diferença entre os sexos.

A partir dessas dimensões (fatores), um expressivo número de trabalhos científicos e acadêmicos de caráter aplicado foi desenvolvido, apresentando suas análises a partir das dimensões encontradas. Entretanto, do ponto de vista da contribuição às dimensões, o trabalho Cultural roots of economic performance: a research note indica uma nova dimensão. Essa dimensão emerge a partir de uma pesquisa conduzida com estudantes chineses (Franke, Hofstede e Bond, 1991). A questão central dessa pesquisa, baseada nos conceitos de Porter (1990), era verificar a relação das características da cultura das nações com a influência das nações na vantagem competitiva. A nova dimensão encontrada é o Dinamismo Confunciano (Confuncian Dynamism). A seguir são apresentadas as dimensões culturais (Hofstede e McCrae, 2004; Hofstede, 2002, 2001, 1980a, 1978):

v Distância do Poder: representa o nível de tolerância dos membros menos influentes de organizações e instituições (como a família) em aceitar e esperar; o poder é distribuído desigualmente. Poder e desigualdade são fatos fundamentais de qualquer sociedade, e qualquer pessoa com alguma experiência internacional estará atenta de que "todas as sociedades são desiguais, mas algumas são mais desiguais que outras" (Hofstede e McCrae, 2004:62).

v Resistência à Incerteza: trata da tolerância de uma sociedade em relação à ambiguidade. Indica até que ponto uma cultura se sente confortável ou 
desconfortável em situações desestruturadas. Situações desestruturadas são desconhecidas, surpreendentes e diferentes do que é habitual. Culturas que evitam a incerteza tentam minimizar a possibilidade de tais situações por leis e regras rígidas. Por um lado, as culturas que evitam a incerteza são emocionalmente mais nervosas. Por outro lado, as culturas que aceitam a incerteza são tolerantes a opiniões diferentes; tentam reagir dentro do possível, em geral são mais relativistas e permitem correntes de pensamento fluirem livremente. As pessoas nessas culturas são mais fleumáticas e pensativas. A resistência à incerteza é relacionada em nível de ansiedade cultural ou neuroses (O'Keefe \& O’Keefe, 2004; Hofstede \& McCrae, 2004);

v Individualismo/Coletivismo: refere-se ao grau em que os indivíduos são integrados em grupos. Em sociedades individualistas, as pessoas dispensam pouca atenção àqueles que não estão diretamente relacionados a seus círculos. Já nas sociedades coletivistas, as pessoas são desde a criação até a maturidade integradas em grupos fortes, aderentes, frequentemente as famílias estendidas (com tios, tias e avós) os protegendo em troca de lealdade inquestionável. A palavra coletivismo neste caso não possui nenhum significado político: recorre ao grupo, não para o Estado. Em resumo, mede o quanto as pessoas recorrem e se engajam em grupos, o quanto cuidam primeiramente de si em detrimento do coletivo (Blanton \& Barbuto Jr., 2005; Hofstede \& McCrae, 2004; Franke, Hofstede e Bond, 1991);

- Masculinidade/Feminilidade: é a distribuição de papéis emocionais entre os sexos; essa é uma questão fundamental para qualquer sociedade. A masculinidade está relacionada à competição, ao posicionamento afirmativo. A feminilidade aproxima-se de um comportamento modesto e atencioso em relação aos outros. Outro fator que distingue culturas com características "masculinas" e "femininas" é o nível de diferenças ou de distanciamento entre as pessoas pelo gênero sexual. Sociedades onde há diferenças latentes são consideradas como "masculinas", o inverso são consideradas "femininas" (Hofstede \& McCrae, 2004, Hofstede, 1983);

v Dinamismo Confuciano: é a aceitação da legitimidade de hierarquia, a avaliação da perseverança, sem ênfase própria e baseada na tradição e nas obrigações sociais. Conforme Franke, Hofstede e Bond (1991), essa dimensão está significativamente correlacionada com o crescimento dos países que seguem esse tipo de orientação espiritual e comportamental. Os ensinamentos de Confúcio têm uma influência profunda para a maioria dos países da Ásia. Os valores de Confúcio incluem na economicidade, 
na persistência com resultados lentos, na adaptação de tradições para um contexto moderno, na aceitação de relações desiguais, na preocupação com a virtude. Estas características fazem os asiáticos se tornarem diferentes em termos de gestão e de trabalho (Chang, 2003; Franke, Hofstede e Bond, 1991).

Na realidade, essas dimensões são independentes e não correlacionadas; entretanto, seus opostos se posicionam em um continuum. O quadro 1 procura caracterizar as diferenças entre as 4 (quatro) principais dimensões culturais de Hofstede. Já o quadro 2 busca brevemente ilustrar uma das aplicações das dimensões culturais para analisar comportamento entre populações de países distintos. Nesse caso, são apresentadas algumas diferenças entre os brasileiros e os americanos.

Além disso, as implicações das dimensões culturais de Hofstede repercutem inclusive na consistência e na dita universalidade das Teorias Organizacionais (Hofstede, 1993, 1994). Conforme Hofstede (1993), a importância dada ao gestor (management) nos Estados Unidos e na Alemanha é significativamente diferente. Essas diferenças implicam inconformidades de aplicação das teorias de gestão formuladas pela academia americana em outros contextos culturais. O autor avança nessa discussão apresentando as diferenças de opiniões entre Frederic Wislon Taylor e Henry Fayol sobre a abordagem necessária para a gestão. Ele sustenta que seus contextos culturais determinaram essas abordagens. Por consequência, a aplicação de uma abordagem ou outra deve ser relativizada em relação ao contexto cultural onde a organização se insere.

\section{Quadro 1}

A mensuração e a escala das dimensões culturais de Hofstede

\begin{tabular}{|c|c|c|c|c|}
\hline Escala & $\begin{array}{l}\text { Distância do } \\
\text { Poder }\end{array}$ & $\begin{array}{l}\text { Resistência à } \\
\text { Incerteza }\end{array}$ & $\begin{array}{l}\text { Individualismo } \\
\text { e Coletivismo }\end{array}$ & $\begin{array}{l}\text { Masculinidade e } \\
\text { Feminilidade }\end{array}$ \\
\hline Alto & $\begin{array}{c}\text { Diferencial social } \\
\text { (hierarquia do } \\
\text { status) }\end{array}$ & $\begin{array}{l}\text { Relações formais } \\
\text { (estrutura, rituais) }\end{array}$ & $\begin{array}{l}\text { Autodetermina- } \\
\text { ção (crescimen- } \\
\text { to pessoal) }\end{array}$ & $\begin{array}{c}\text { Relações de controle } \\
\text { (comportamento } \\
\text { competitivo) }\end{array}$ \\
\hline Baixo & $\begin{array}{l}\text { Integração social } \\
\text { (status igual) }\end{array}$ & $\begin{array}{c}\text { Relações informais } \\
\text { (menos controle) }\end{array}$ & $\begin{array}{c}\text { Coletividade } \\
\text { (harmonia de } \\
\text { grupo) }\end{array}$ & $\begin{array}{l}\text { Criação de relações } \\
\text { (menos competitivo) }\end{array}$ \\
\hline
\end{tabular}

Fonte: Chang, 2003:569. 
Quadro 2

Classificação de Brasil e Estados Unidos de acordo com as dimensões de Hofstede

\begin{tabular}{|llc|}
\hline \multicolumn{1}{|c}{ Dimensões Culturais } & \multicolumn{1}{c|}{ Brasil } & Estados Unidos \\
\hline Distância do Poder (Alto/Baixo) & Relativamente alto & Relativamente baixo \\
Resistência à Incerteza (Alto/Baixo) & Relativamente forte & Relativamente baixa \\
Individualismo e Coletivismo & Mais coletivista & Individualista \\
Masculinidade e Feminilidade & Posição central & Tendendo à masculinidade \\
\hline
\end{tabular}

Fonte: O'Keefe e O'Keefe, 2004:615.

Contudo, apesar do número significativo de trabalhos baseados em Hofstede, as dimensões culturais propostas sofrem críticas. Hofstede (2002) elenca cinco críticas realizadas à sua abordagem, a saber:

v Surveys (levantamentos) não são satisfatórias para medir diferenças culturais;

v Nações não são as melhores unidades por estudar culturas;

จ Um estudo das subsidiárias de uma companhia não pode prover informação sobre culturas nacionais inteiras;

、 Os dados de IBM são velhos e, por consequência, obsoletos;

、 Quatro ou cinco dimensões não são o bastante.

Para cada uma das críticas Hofstede (1993) oferece contra-argumentos e procura fundamentá-los em seus textos e outros trabalhos. De fato, apesar das possíveis limitações é necessário reconhecer a aplicabilidade, o poder de comunicação dos resultados e o grau do entendimento que as dimensões propostas proporcionam. A seguir são apresentadas as dimensões culturais segundo Fons Trompenaars.

\section{As dimensões culturais de Fons Trompenaars}

Basicamente são três os objetivos de Trompenaars (1994), a saber: i) acabar com a ideia de que há a melhor forma de gerenciamento e organização; ii) fornecer aos interessados uma melhor noção de sua própria cultura e como lidar em um contexto empresarial; e iii) oferecer algumas ideias sobre o dilema global versus local com o qual se deparam as organizações internacionais. 
Nesse sentido Trompenaars (1994) sugere que a base do sucesso seria entender a própria cultura, as premissas e as expectativas sobre como as pessoas deveriam pensar e agir. Assim a cultura pode se explicar por diversas camadas. Trompenaars (1996) propõe um modelo para a cultura que pode ser observado na figura. Na sequência são detalhados os diferentes níveis.

Figura

Modelo de cultura

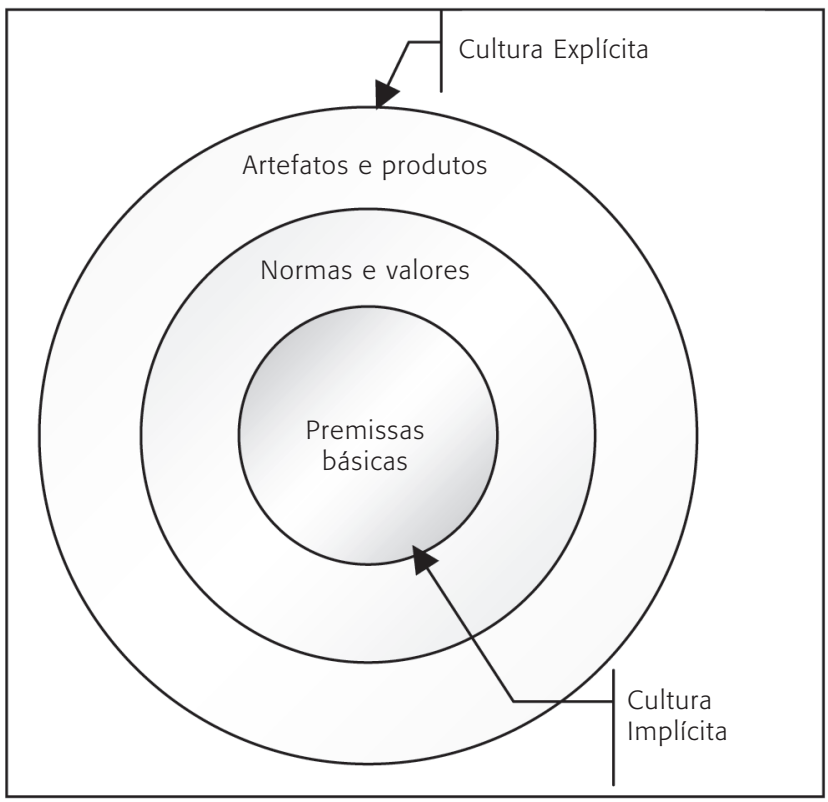

Fonte: Trompenaars, 1996:51.

จ Nível externo (produtos explícitos): é a realidade observável da língua, comida, arquitetura, agricultura, templos, vestimentas e arte. Cada opinião que se expressa com relação à cultura explícita geralmente diz mais sobre de onde as pessoas vêm do que sobre a comunidade que se está julgando. Os preconceitos começam na maioria das vezes nesse nível simbólico e observável (Trompenaars, 1996, 1994);

、 Nível intermediário (normas e valores): as normas são os sentimentos mútuos que um grupo tem do que é certo e errado. As normas podem se desenvolver em um nível formal, como leis aprovadas, e em um nível informal, como controle social. Os valores, por outro lado, determinam a 
definição de "bom" ou "mau" e estão intimamente relacionados aos ideais compartilhados por um grupo. Uma cultura é relativamente estável quando as normas refletem os valores de grupos. Pode-se definir que a norma diz respeito a como as pessoas devem se comportar; os valores relacionamse à forma que um indivíduo deseja se comportar (Trompenaars, 1996, 1994);

- Centro: premissas sobre a existência: o valor mais básico pelo qual as pessoas lutam diariamente é a sobrevivência. Por exemplo, a eterna luta entre o homem e a natureza existe em várias partes do mundo: holandeses (diques); suíços (avalanches); africanos (secas); siberianos (frio).

"Entender o centro do modelo é a chave para o sucesso de quem trabalha outras culturas" (Trompenaars, 1996:51). Uma cultura organizacional ou cultura funcional específica nada mais é do que as formas como os grupos se organizaram no decorrer dos anos, para resolver os problemas e desafios apresentados a eles. As mudanças na cultura acontecem, pois as pessoas percebem que determinados meios antigos de se fazer as coisas não funcionam mais (Fonseca, 2005; Trompenaars, 1994). Assim, a cultura se apresenta em diferentes níveis:

- A mais alta encontra a cultura de uma sociedade nacional ou regional.

- A forma como as atitudes se expressam dentro de uma organização específica é descrita como cultura empresarial.

- A cultura de determinados departamentos dentro das organizações: marketing; pessoal; pesquisa etc.

O entendimento da cultura passa por compreender que toda cultura (as pessoas) se distingue das outras por meio de soluções específicas a determinados problemas (desafios). Em geral, esses problemas (desafios) podem ser categorizados de três formas: i) os que surgem dos relacionamentos com as outras pessoas; ii) os que surgem relacionados com a passagem do tempo; e; iii) os que se relacionam com o ambiente (Fonseca, 2005, Trompenaars e Woollianms, 2003; Trompenaars, 1996, 1994). Com base nas soluções apresentadas por diferentes culturas a esses problemas universais, podem-se identificar sete dimensões fundamentais da cultura. São elas (Trompenaars, 1994):

1) Problemas de relacionamentos com as pessoas

a) Universalismo/Particularismo (regras versus relacionamento): A abordagem universalista é a seguinte: "É possível definir o que é bom e 
o que é ruim e esse critério sempre se aplica". Nas culturas particularistas dá-se mais atenção às obrigações dos relacionamentos e circunstâncias específicas. Em vez de pressupor que uma lei boa deva ser sempre seguida, o raciocínio particularista é que a amizade tem obrigações especiais e, portanto, pode ser prioritária. Dá-se menos atenção a códigos sociais abstratos. Os executivos das duas sociedades tenderão a pensar que o outro é corrupto. Um universalista dirá dos particularistas: "não pode confiar neles, porque ele vão sempre ajudar os amigos"; porém os particularistas dirão: "não se pode confiar neles, eles não ajudam nem o próprio amigo".

b) Individualismo/Coletivismo (grupo versus individual): Nesta categoria são levantadas as seguintes situações: As pessoas se veem basicamente como indivíduos ou como parte de um grupo? É mais importante concentrar-se nos indivíduos para que possam contribuir para a coletividade ou é mais importante considerar a coletividade já que é comum a vários indivíduos? Práticas individualistas como promoções, por conquistas reconhecidas e remuneração de desempenho pressupõem que os indivíduos busquem diferenciação dentro do grupo; nada disso pode na cultura mais coletivista. O individualismo é visto como uma característica de uma sociedade modernizante, ao passo que o coletivismo como de sociedades mais tradicionais e as do antigo comunismo; mas os países chamados Tigres Asiáticos levantam dúvidas sobre esta afirmação. E também nos países ocidentais tem-se a visão de que os gênios individuais criam empresas e produtos, merecem altos salários e créditos individuais, mas deve-se perguntar qual a participação dos empregados envolvidos.

c) Neutro/Emocional (a variedade de sentimentos expressos): Nos relacionamentos entre as pessoas, razão e emoção desempenham seu papel. A afetividade, ou seja, a demonstração das emoções ou a imparcialidade emocional. Os membros da cultura afetivamente neutra não revelam seus sentimentos, mas os mantêm controlados e reprimidos. Por outro lado, nas culturas com grau de afetividade as pessoas demonstram seus sentimentos; entretanto, isto não quer dizer que as culturas neutras são frias ou sem sentimentos. A natureza das intenções deve ser objetiva e imparcial ou é aceitável expressar emoção? Em países da América do Norte os relacionamentos empresariais são geralmente instrumentos para se chegar ao fim, as emoções são reprimidas, pois acreditam que podem atrapalhar as negociações; mas nos países do hemisfério Sul os negócios são questões humanas e toda gama de emoções é considerada apropriada. 
d)Específico/Difuso (a variedade de envolvimentos): Nas culturas específicas (contexto específico e simples), o gerente separa o relacionamento que tem com um subordinado de outras atividades. Mas na cultura difusa (contexto difuso e complexo), todos os espaços de vida e todos os níveis de personalidade tendem a permear os outros. Quando uma pessoa está envolvida em um relacionamento empresarial, há contato real e pessoal, em vez do relacionamento específico recomendado no contrato. Em muitos países não se dão preferências a um relacionamento difuso, mas esse é necessário antes que se dê andamento aos negócios. A estratégia difusa de negócios é cercar o estranho, conhecendo-o difusamente e tratar de pontos específicos do negócio apenas mais tarde, quando os relacionamentos de confiança já tiverem sido estabelecidos. As culturas difusas tendem a ter uma menor rotatividade e mobilidade de empregados, devido à importância da lealdade e da multiplicidade de elos humanos.

e) Conquista/Atribuição (como se confere status): Todas as sociedades concedem mais status a determinados membros do que a outros. Em algumas sociedades com base em suas conquistas, o que é chamado status conquistado. Outras diferenciam idade, sexo, classe e instrução, o que é chamado status atribuído. Conquista significa que você é julgado pelo que fez recentemente e por seu histórico. Atribuição é o que lhe conferem de status por seu nascimento, parentesco, sexo ou idade; mas também por suas conexões (quem você conhece) e sua formação acadêmica.

2) Problemas de relacionamentos com a passagem do tempo

a) Atitudes em relação ao tempo: As formas como as sociedades encaram o tempo também diferem. Para algumas sociedades, o que alguém conquistou no passado não é tão importante. É mais importante saber seus planos no futuro. Em outras sociedades, você impressiona mais contando seus feitos passados do que os presentes. São diferenças culturais que influenciam enormemente nas atividades empresariais. Existem três tipos de culturas: i) voltada ao presente: relativamente atemporal, sem tradição e que ignora o futuro; ii) voltada ao passado, preocupada principalmente em manter e recuperar as tradições no presente; e; iii) voltada ao futuro, aquela que deseja um futuro melhor e prepara-se para realizá-lo.

3) Problemas de relacionamentos com o ambiente

a) Atitudes em relação ao ambiente: Algumas culturas acham que o ponto focal que afeta suas vidas e as origens do vício e da virtude residem 
na pessoa. Neste caso, as motivações e valores vêm de dentro. Outras culturas veem o mundo como mais forte do que os indivíduos. Considerar a natureza como algo a ser temido ou imitado. As sociedades que conduzem negócios desenvolveram duas orientações em relação à natureza. A primeira acredita que podem e devem controlar a natureza (direcionada internamente). A segunda, por sua vez, acredita que o homem é parte da natureza e deve submeter-se a suas leis, direções e forças (direcionada externamente). Existem formas de adaptação às influências externas que podem ser comprovadamente eficazes. Aceitar a direção dos clientes, as forças do mercado ou as novas tecnologias pode ser mais vantajoso do que se opor a elas, priorizando suas próprias preferências.

Segundo Trompenaars (1994), tão importante quanto os problemas e suas dimensões são as características. São nas características que as dimensões são evidenciadas e percebidas. Nesse nível as diferenças culturais afloram e, dessa reação, potenciais problemas podem surgir. Na realidade, a compreensão das dimensões colabora para o entendimento das reações e, por consequência, um melhor aproveitamento dos pontos positivos das diferenças. O quadro 3 procura sintetizar as características de cada uma das dimensões relacionadas com os relacionamentos, enquanto os quadros 4 e 5 focam os problemas relativos ao tempo e ao ambiente, respectivamente.

Quadro 3

Características dos problemas relativos a relacionamentos

\begin{tabular}{|c|c|c|}
\hline & Características \\
\hline \multirow{2}{*}{ 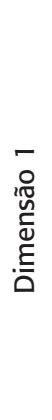 } & Universalistas & $\begin{array}{l}\text { - Concentra-se mais nas regras do que nos relacionamentos; } \\
\text { - A pessoa de confiança é aquela que honra seus contratos/palavra; } \\
\text { - Há apenas uma verdade ou realidade, aquela que está no contrato; } \\
\text { - Os argumentos são racionais, profissionais e as atitudes são impessoais. }\end{array}$ \\
\hline & Particularistas & $\begin{array}{l}\text { - Concentra-se mais nos relacionamentos do que nas regras; } \\
\text { - Os contratos legais podem ser modificados; } \\
\text { - Uma pessoa de confiança é aquela que honra a reciprocidade em mudanças; } \\
\text { - Os relacionamentos evoluem; } \\
\text { - Os argumentos são por rodeios ou irrelevantes, as atitudes são pessoais e } \\
\text { emocionais. }\end{array}$ \\
\hline
\end{tabular}

Continuo 


\begin{tabular}{|c|c|c|}
\hline \multirow{2}{*}{ 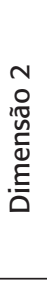 } & Individualistas & $\begin{array}{l}\text { - Decisões tomadas imediatamente pelos seus representantes; } \\
\text { - As pessoas realizam-se sozinhas e assumem responsabilidades pessoais, o que } \\
\text { demonstra que esta pessoa é respeitada pela empresa. }\end{array}$ \\
\hline & Coletivistas & $\begin{array}{l}\text { - Decisões levadas pelos delegados à organização; } \\
\text { - As pessoas realizam em grupos que assumem responsabilidades conjuntas; } \\
\text { - Conduzir o negócio cercado por vários ajudantes significa que essa pessoa tem } \\
\text { muito prestígio na empresa. }\end{array}$ \\
\hline \multirow{2}{*}{ 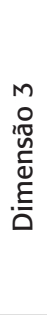 } & Neutras & $\begin{array}{l}\text { - Não revelam o que estão pensando ou sentindo. Podem revelar tensão no rosto } \\
\text { e postura; } \\
\text { - Contato físico, gestos ou expressões são muitas vezes considerados tabu; } \\
\text { - As frases são muitas vezes expressas de forma monótona. }\end{array}$ \\
\hline & Afetivas & $\begin{array}{l}\text { - Revelam o que estão pensando ou sentindo verbalmente e não verbalmente; } \\
\text { - As emoções fluem facilmente, veementes e sem inibição; } \\
\text { - Manifestações acaloradas, vitais e animadas são admiradas; } \\
\text { - As frases são declamadas fluentes e dramaticamente. }\end{array}$ \\
\hline \multirow{2}{*}{ 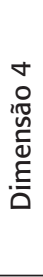 } & Específicas & $\begin{array}{l}\text { - As agendas pessoais e profissionais são mantidas separadamente; } \\
\text { - Direto ao ponto, objetivo no trato preciso, direto e transparente; } \\
\text { - Os conflitos de interesse pessoais não são bem-vindos. }\end{array}$ \\
\hline & Difusas & $\begin{array}{l}\text { - As questões pessoais e profissionais se interceptam; } \\
\text { - Considera a situação do empregado como um todo antes de julgá-lo; } \\
\text { - Moralidade altamente circunstancial dependendo da pessoa e do contexto } \\
\text { encontrado. }\end{array}$ \\
\hline \multirow{2}{*}{ 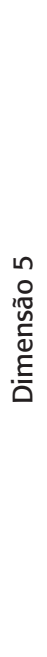 } & Conquista & $\begin{array}{l}\text { - Uso de títulos apenas quando relevante à competência necessária à tarefa; } \\
\text { - O respeito pelo superior na hierarquia é baseado no grau de eficácia com que } \\
\text { o trabalho é executado e na adequação do conhecimento; } \\
\text { - A maioria dos gerentes seniores tem idade e sexo variados e demonstra com- } \\
\text { petência em funções específicas; } \\
\text { - O gerenciamento por metas e remuneração pelo desempenho são ferramentas } \\
\text { eficazes; } \\
\text { - As decisões são contestadas com base nos aspectos técnicos e funcionais. }\end{array}$ \\
\hline & Atribuição & $\begin{array}{l}\text { - Uso extensivo de títulos, especialmente quando esses esclarecem o status na } \\
\text { empresa; } \\
\text { - O respeito pelo superior na hierarquia é considerado uma medida do compro- } \\
\text { misso com a empresa e sua missão; } \\
\text { - A maioria dos gerentes seniores é de homens de meia-idade e qualificados por } \\
\text { seu histórico; } \\
\text { - O gerenciamento por metas e a remuneração pelo desempenho são menos } \\
\text { eficazes do que recompensas diretas oferecidas pelo gerente; } \\
\text { - As decisões só são contestadas por pessoas com maior autoridade. }\end{array}$ \\
\hline
\end{tabular}

Fonte: Adaptado de Trompennars (1994). 


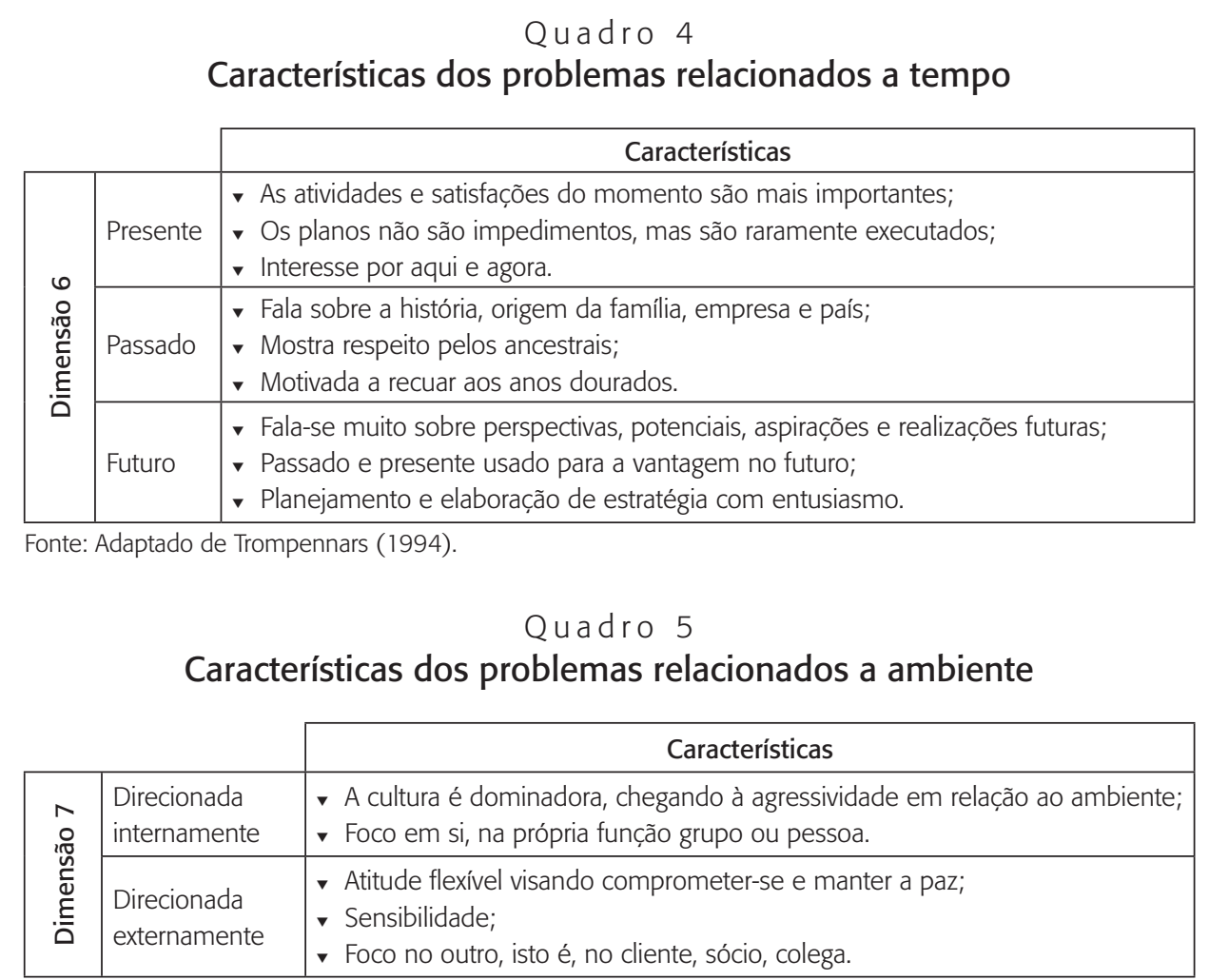

Fonte: Adaptado de Trompennars (1994).

A seguir se apresentam alguns pontos de convergência entre Trompennars e Hofstede. Cabe ressaltar que além dos modelos desses autores existem outras proposições de dimensões culturais. Não é objetivo dessa revisão esgotar o assunto, mas apresentar alguns elementos teóricos que possam contextualizar a discussão.

\section{Sinergias e alergias entre as dimensões propostas por Hofstede e Trompenaars}

Segundo Hofstede (1980b, 1984, 1993, 1994), a aquisição de valores está integrada ao processo de socialização, que se inicia na infância, com a família, prossegue na escola e se completa nas relações de trabalho. A distinção destas três etapas é proposta por Hofstede para a diferenciação dos "tipos" de valores adquiridos. Na primeira etapa são aprendidos os valores da cultura nacional, 
na segunda, no nível da cultura ocupacional; no terceiro estágio se adquirem os valores no nível da cultura organizacional.

Para Trompenaars (1994), a cultura organizacional seria formada não apenas pela tecnologia e pelo mercado em que atua, mas também pelos valores compartilhados por seus empregados e líderes. Para o autor, as pessoas copiam os modelos ou ideais familiares quando criam uma empresa; existindo três aspectos da estrutura organizacional importantes ao determinar a cultura da empresa: i) a relação global entre empregados e sua empresa; ii) os sistemas hierárquicos de autoridade; iii) as visões gerais dos empregados sobre destino, objetivo e metas da empresa e seu papel em relação a eles.

Os traços culturais que tratam da relação do indivíduo com o grupo estão presentes em várias das dimensões de cultura apresentadas por Hofstede e Trompenaars. Ambos identificam o coletivismo e o individualismo como uma dimensão da cultura. Trompenaars (1994) aborda que esta dimensão trata do conflito entre o interesse do grupo e o interesse de cada indivíduo. Trompenaars (1994) descreve o individualismo como "uma orientação primordial ao eu", e o coletivismo como "uma orientação primordial aos objetivos e metas comuns". Convenientemente, Trompennars (1994) esclarece que uma nação coletivista não é aquela que cerceia o livre-arbítrio de todos os indivíduos, e sim, que é desejo individual dos componentes do grupo que suas ações se reflitam positivamente no grupo como um todo.

As definições de Hofstede e de Trompenaars para esta dimensão são semelhantes, não havendo diferenças nos conceitos centrais declarados por ambos. As dimensões que tratam das relações sociais e de poder são agrupadas nos resultados das pesquisas de Hofstede (distância do poder) e Trompenaars (conquista/atribuição). Segundo Hofstede (1980b, 1984, 1993, 1994), em países identificados com alto grau de distância do poder os empregados frequentemente demonstram medo em não concordar com seus superiores. Também revelam preferir chefes autocráticos ou paternalistas a chefes consultivos. Superiores e subordinados não se colocam em patamar de igualdade e o sistema hierárquico se baseia na desigualdade existente. Algumas características encontradas nesse tipo de ambiente organizacional são: estruturas hierárquicas verticalizadas, poder concentrado nas mãos de poucas pessoas, privilégios para os níveis hierárquicos mais altos, chefes autocráticos e paternalistas.

A relação com a hierarquia é identificada nas pesquisas de Trompenaars na dimensão status pela conquista e status atribuídos. O resultado da pesquisa de Trompenaars identificou alta correlação entre a orientação religiosa e a forma de concessão do status. As sociedades predominantemente católicas, budistas e hinduístas tendem a orientar o status pela atribuição, e as sociedades 
predominantemente protestantes tendem a orientar o status pela conquista. Vale dizer que Hofstede não citou nenhuma relação entre a orientação religiosa e o grau de distância do poder nas culturas nacionais.

Nas dimensões descritas por Hofstede com as dimensões descritas por Trompenaars podem-se notar elementos comuns, e por vezes complementares. Por exemplo, uma cultura onde predomina o status pela conquista seria, provavelmente, uma cultura com baixo grau de distância do poder, pois não seria compatível que em uma sociedade que valoriza o mérito houvesse uma grande preocupação em não aceitar insubordinações ou desafios à hierarquia.

Em países caracterizados pela baixa distância de poder, superiores e subordinados consideram uns aos outros essencialmente como iguais, e o sistema hierárquico das organizações reflete uma desigualdade que é estabelecida só por conveniência, pois o subordinado de hoje pode ser o superior de amanhã (Hofstede, 1980b, 1984, 1993, 1994). Tanto superiores quanto subordinados preferem um estilo consultivo a um estilo autoritário.

\section{Referências}

BLANTON, Karen K.; BARBUTO JR., John E. Cultural constraints in the workplace: an experiential exercise utilizing Hofstede's dimensions. Journal of Management Education, v. 29, n. 4, p. 654-666, 2005.

CANEN, Alberto G.; CANEN, Ana. Organizações multiculturais. Rio de Janeiro: Ciência Moderna, 2005.

CHANG, Lieh-Ching. An examination of cross-cultural negotiation: using Hofstede framework. Journal of America Academy of Business, v. 2, n. 2, p. 567-570, 2003.

FONSECA, Ana Carolina. A influência das diferenças culturais entre Brasil e Estados Unidos na implantação do Balanced Scorecard em empresas brasileiras. Dissertação (mestrado em ciências contábeis) — Programa de Pós-Graduação em Contabilidade da Coppead, Universidade Federal do Rio de Janeiro, 2005.

FRANKE, Richard; HOFSTEDE, Geert; BOND, Michael. Cultural roots of economic performance: a research note. Strategic Management Journal, v. 12, n. 2, p. 165173, 1991.

HARVEY, Francis. National cultural differences in theory and practice: evaluation Hofstede's national cultural framework. Information Technology \& People, v. 10, n. 2, p. 132-146, 1997.

HOFSTEDE, Geert. Cultural constraints in management theories. Academy of Management Executive, v. 7, n. 1 p. 81-94, 1993. 
HOFSTEDE, Geert. Culture's consequences: international differences in work-related values. Bevelry Hills: Sage, 1980a.

HOFSTEDE, Geert. Culture consequences: comparing values, behaviors, institutions and organizations across nations. Thousand Oaks: Sage, 2001.

HOFSTEDE, Geert. Dimensions do not exist: a reply to Brendan McSweeney. Human Relations, v. 55, n. 11, p. 1355-1361, 2002.

HOFSTEDE, Geert. Management scientists are human. Management Science, v. 40, n. 1 p. 4-13, 1994.

HOFSTEDE, Geert. Motivation, leadership, and organization: do American theories apply abroad? Organizational Dynamics, p. 42-63, Summer 1980b.

HOFSTEDE, Geert. The cultural relativity of organizational practices and theories. Journal of International Business Studies, v. 14, n. 14, p. 75-90, 1983.

HOFSTEDE, Geert. The cultural relativity of the quality of life concept. Academy of Management Review, v. 9, n. 3, p. 389-398, 1984.

HOFSTEDE, Geert. The poverty of management control philosophy. Academy of Management Review, v. 3, n. 3 p. 450-461, 1978.

HOFSTEDE, Geert; McCRAE, Robert R. Personality and culture revisited: linking traits and dimensions of culture. Cross-Cultural Research, v. 38, n. 1, p. 52-88, 2004.

LAGROSEN, Stefan. Exploring the impact of culture on quality management. The International Journal of Quality \& Reliability Management, v. 20, n. 5, p. 473-487, 2003.

MELLO, John; STANK, Theodore. Linking firm culture and orientation to supply chain success. International Journal of Physical Distribution \& Logistics Management, v. 35, n. 8, p. 542-544, 2005.

O'KEEFE, Hsu; O'KEEFE, William M. Business behaviors in Brazil and the USA. International Journal of Social Economics, v. 31, n. 6, p. 614-622, 2004.

PORTER, Michael. The competitive advantage of nations. New York: Free Press, 1990.

TROMPENAARS, Fons. Nas ondas da cultura: como entender a diversidade cultural nos negócios. São Paulo: Educator, 1994.

TROMPENAARS, Fons. Resolving international conflict: culture and business strategy. London Business School, v. 7, n. 3, p. 51-88, 1996.

TROMPENAARS, Fons; WOOLLIAMS, Peter. A new framework for managing change across cultures. Journal of Change Management, v. 3, n. 4, p. 361-375, 2003. 